\title{
The Semantic Network at Work and Rest: Differential Connectivity of Anterior Temporal Lobe Subregions
}

\author{
Rebecca L. Jackson, ${ }^{1}$ Paul Hoffman, ${ }^{1,2} \mathbb{Q}^{-}$Gorana Pobric, ${ }^{1}$ and ${ }^{\circledR}$ Matthew A. Lambon Ralph ${ }^{1}$ \\ ${ }^{1}$ Neuroscience and Aphasia Research Unit, School of Psychological Sciences, University of Manchester, Manchester M13 9PL, United Kingdom, and ${ }^{2}$ Centre \\ for Cognitive Ageing and Cognitive Epidemiology, Department of Psychology, University of Edinburgh, Edinburgh EH8 9JZ, United Kingdom
}

The anterior temporal lobe (ATL) makes a critical contribution to semantic cognition. However, the functional connectivity of the ATL and the functional network underlying semantic cognition has not been elucidated. In addition, subregions of the ATL have distinct functional properties and thus the potential differential connectivity between these subregions requires investigation. We explored these aims using both resting-state and active semantic task data in humans in combination with a dual-echo gradient echo planar imaging (EPI) paradigm designed to ensure signal throughout the ATL. In the resting-state analysis, the ventral ATL (vATL) and anterior middle temporal gyrus (MTG) were shown to connect to areas responsible for multimodal semantic cognition, including bilateral ATL, inferior frontal gyrus, medial prefrontal cortex, angular gyrus, posterior MTG, and medial temporal lobes. In contrast, the anterior superior temporal gyrus (STG)/superior temporal sulcus was connected to a distinct set of auditory and language-related areas, including bilateral STG, precentral and postcentral gyri, supplementary motor area, supramarginal gyrus, posterior temporal cortex, and inferior and middle frontal gyri. Complementary analyses of functional connectivity during an active semantic task were performed using a psychophysiological interaction (PPI) analysis. The PPI analysis highlighted the same semantic regions suggesting a core semantic network active during rest and task states. This supports the necessity for semantic cognition in internal processes occurring during rest. The PPI analysis showed additional connectivity of the vATL to regions of occipital and frontal cortex. These areas strongly overlap with regions found to be sensitive to executively demanding, controlled semantic processing.

Key words: anterior superior temporal gyrus; anterior temporal lobe; functional connectivity; language; resting-state fMRI; semantic cognition

\section{Significance Statement}

Previous studies have shown that semantic cognition depends on subregions of the anterior temporal lobe (ATL). However, the network of regions functionally connected to these subregions has not been demarcated. Here, we show that these ventrolateral anterior temporal subregions form part of a network responsible for semantic processing during both rest and an explicit semantic task. This demonstrates the existence of a core functional network responsible for multimodal semantic cognition regardless of state. Distinct connectivity is identified in the superior ATL, which is connected to auditory and language areas. Understanding the functional connectivity of semantic cognition allows greater understanding of how this complex process may be performed and the role of distinct subregions of the anterior temporal cortex.

\section{Introduction}

The anterior temporal lobe (ATL) is critical for semantic cognition. Modality-specific information from "spoke" regions converges in and interacts with the ATL "hub," creating multimodal conceptual representations (Rogers et al., 2004; Patterson et al.,

Received Aug. 9, 2015; revised Nov. 20, 2015; accepted Dec. 9, 2015.

Author contributions: R.L.J., P.H., G.P., and M.A.L.R. designed research; R.L.J. performed research; R.L.J., P.H., G.P., and M.A.L.R. analyzed data; R.L.J., P.H., G.P., and M.A.L.R. wrote the paper.

This work was supported by a doctoral studentship and prize from the Engineering and Physical Sciences Research Council (R.L.J.) and the Medical Research Council (Program Grant MR/J004146/1 to M.A.L.R.). RL was supported by an EPSRC-funded studentship.

The authors declare no competing financial interests.
2007; Lambon Ralph, 2014). Until recently, the ATL has been viewed as one homogenous region due to the low spatial specificity of neuropsychological data. However, cytoarchitectural differences within the ATL hint at the presence of distinct, yet

This article is freely available online through the J Neurosci Author Open Choice option.

Correspondence should be addressed to Professor Matthew A. Lambon Ralph, Neuroscience and Aphasia Research Unit (NARU), School of Psychological Sciences (Zochonis Building), University of Manchester, Brunswick Street, Manchester M13 9PL, UK. E-mail: matt.lambon-ralph@manchester.ac.uk.

DOI:10.1523/JNEUROSCI.2999-15.2016

Copyright $@ 2016$ Jackson et al.

This is an Open Access article distributed under the terms of the Creative Commons Attribution License Creative Commons Attribution 4.0 International, which permits unrestricted use, distribution and reproduction in any medium provided that the original work is properly attributed. 
graded subregions (Brodmann, 2006; Ding et al., 2009). Recent neuroimaging, neurostimulation, electrophysiology, and detailed patient assessments suggest that the center point of the multimodal hub region sits within the ventral ATL (vATL; Lüders et al., 1986; Lüders et al., 1991; Pobric et al., 2007; Butler et al., 2009; Lambon Ralph et al., 2009; Binney et al., 2010; Mion et al., 2010; Visser and Lambon Ralph, 2011; Visser et al., 2012; Shimotake et al., 2015). Other ATL subregions may differ from the vATL in terms of function and connectivity in a graded fashion (Visser and Lambon Ralph, 2011; Binney et al., 2012). For example, the anterior superior temporal gyrus (aSTG) and superior temporal sulcus (STS) may be particularly involved in processing the meaning of auditory and verbal stimuli (Scott et al., 2000; Spitsyna et al., 2006; Visser and Lambon Ralph, 2011; Visser et al., 2012) and may reflect structural connections to primary auditory regions (Morán et al., 1987; Binney et al., 2012). Alternatively, the aSTG's structural connection to the inferior frontal gyrus (IFG) (Duffau et al., 2005; Friederici, 2011) could suggest a role in semantic control (Hoffman et al., 2015).

Neural processing is dynamic and may be best understood via the interactions between multiple areas (Mesulam, 1990; McIntosh, 1999; Bressler and Menon, 2010; Meehan and Bressler, 2012). Determining the pattern of connectivity across the ATL allows identification of distinct subregions and helps inform their function. Prior investigations of the connectivity of circumscribed polar and lateral ATL regions (Simmons et al., 2010; Turken and Dronkers, 2011; Pascual et al., 2015; Mesulam et al., 2014) were unable to demonstrate this pattern of connectivity for two key reasons. First, only one location was studied so comparison was not possible. Second, there is signal loss and distortion in the ATL (Binney et al., 2010; Embleton et al., 2010; Visser et al., 2010b; Halai et al., 2014), an issue highlighted in previous seedbased and whole-brain resting-state studies (Ding et al., 2009; Zuo et al., 2012; Wig et al., 2014).

Semantic cognition depends upon a distributed network (Eggert, 1977), yet the underlying functional connectivity has not been established. In addition to ATL subregions, semantic cognition consistently involves IFG, medial prefrontal cortex (mPFC), posterior middle temporal gyrus (pMTG), and lateral parietal regions (Binder et al., 2009; Jefferies, 2013; Noonan et al., 2013). Semantic cognition is considered a major component of processing during the resting state (Binder et al., 1999; Binder et al., 2009). Despite this, the resting-state connectivity of the vATL region crucial for semantic cognition has not been explored, likely due to poor signal in this region.

In this study, we probed the resting-state connectivity of various ATL subregions, including the vATL area considered to be critical for semantic cognition. This allowed us both to identify ATL subregions with distinct connectivity patterns and to explicate the network responsible for semantic cognition. A dual-echo gradient echo planar imaging (EPI) paradigm was used to ensure full ATL coverage (Halai et al., 2014). The extent and function of the semantic network was thoroughly explored by assessing the connectivity of the vATL in both resting-state fMRI and fMRI data from an active semantic task assessed using a psychophysiological interaction (PPI) analysis. Semantic processing may differ between the restingstate and active tasks (e.g., resting-state semantics may be less goal directed and stimulus driven), yet both are believed to depend on core semantic regions. Convergence between the connectivity in active and resting states would provide com- pelling evidence of a core network responsible for multimodal semantic cognition.

\section{Materials and Methods}

\section{Participants}

Resting-state scans were collected for 78 participants (57 female, age range $18-42$, average age 24.71 years, SD 5.49 years), 24 of whom also completed a dual gradient echo fMRI study of semantic decision making reported previously ( 15 female, age range $20-42$, average age 25.63 years, SD 56.36 years; Jackson et al., 2015). Participants were strongly right handed (minimum laterality quotient 50 , average 85.85 , SD 14.91 on the Edinburgh Handedness Inventory; Oldfield, 1971). Participant's vision was normal or corrected to normal. All participants gave informed consent and the study was approved by the local ethics board.

\section{Procedure}

Scanning was conducted using a Phillips Achieve 3.0 T system with 32 channel SENSE coil with a sense factor of 2.5. Noise-cancelling Mk II+ headphones were worn inside the scanner (MR Confon). A structural reference was obtained with an in-plane resolution of 0.938 and a slice thickness of 1.173 . Whole-brain coverage was obtained with a field of view of $240 \times 240 \mathrm{~mm}$, which was tilted up to $45^{\circ}$ off the AC-PC line to reduce the effect of ghosting on the temporal pole. The TR was 2.8 with a flip angle of $85^{\circ}$, resolution matrix of $80 \times 80$, reconstructed voxel size of $3 \mathrm{~mm}$, and slice thickness of $4 \mathrm{~mm}$. A total of 130 volumes were collected over $6.25 \mathrm{~min}$ for the resting-state scan. Three runs of task data for each participant were included in the PPI analysis. Run length was $10 \mathrm{~min}$ and 211 volumes were collected per task run. The imaging parameters for the resting-state and task scans were identical.

A dual gradient echo EPI technique was used. This involves parallel acquisition at a short echo $(12 \mathrm{~ms})$ leading to less signal loss in areas of high magnetic susceptibility and a standard long echo $(35 \mathrm{~ms})$ to maintain high contrast sensitivity throughout the brain. The results from the two echoes were combined using linear summation, previously shown to be optimal (Poser et al., 2006; Halai et al., 2014). The resultant reduction in signal dropout is greatest within inferior temporal and orbitofrontal regions including the vATL, an area of key interest in this investigation (Poser and Norris, 2007, 2009; Halai et al., 2014). Mean temporal signalto-noise ratio (TSNR) is shown in Figure $1 \mathrm{~A}$. TSNR exceeded 40 throughout all subregions of the ATL and was considerably greater in the majority of regions.

During the resting-state scans, participants were asked to fixate on a cross and lie still (Van Dijk et al., 2012). For the active task, a PPI analysis was conducted on three runs of data reported by Jackson et al. (2015), which included a semantic and baseline task. The semantic task involved a triad judgment in which participants were asked to match a probe word (e.g., "hen") to the most semantically related of two choices. The target was either strongly associated (e.g., "cage") or conceptually similar (e.g., "robin") to the probe. Foils were unrelated to probes and targets. Formal whole-brain analysis showed no significant differences between the regions involved in these two conditions and no further distinction is made here. In the control task, participants were asked to decide which of two letter strings (containing Greek and English letters) overlapped the most with the probe string. The control task was designed to act as a high-level baseline to ensure that the results were not merely the product of an input, output, or domain-general executive processes and to ensure little off-task semantic processing, which is likely to reduce the difference in semantic regions between the tasks (Binder et al., 2009; Visser et al., 2010a). The control task therefore needed to be at least as challenging as the semantic task, which proved to be the case [control task: mean RT = $2076 \mathrm{~ms}(\mathrm{SD}=265)$; semantic task: mean RT $=1719 \mathrm{~ms}(\mathrm{SD}=273)$; $\left.t_{(23)}=9.74, p<0.05\right]$. Stimuli were presented in miniblocks of $15 \mathrm{~s}$ each containing three trials. Both tasks started with a central fixation cross presented for $1000 \mathrm{~ms}$, followed by presentation of the stimuli for 4000 ms. During this time, participants responded by pressing one of two buttons.

ROIs

Independently derived peak coordinates were taken from the wholebrain univariate analysis in key semantic areas identified from the liter- 
ature, including ventral and superior ATL, posterior MTG, IFG, medial prefrontal cortex, and angular gyrus. Within the ATL, a ventral region has been shown to be critical (Binney et al., 2010; Visser and Lambon Ralph, 2011; Visser et al., 2012). The role of the aSTG in multimodal semantics is less clear because it may be more important for auditory and verbal stimuli (Spitsyna et al., 2006; Visser and Lambon Ralph, 2011; Visser et al., 2012). A spherical ROI with a $10 \mathrm{~mm}$ radius was constructed around the peak coordinate from the whole-brain univariate analyses of the active fMRI data in ventral and superior ATL, posterior MTG, IFG, and medial prefrontal cortex (Jackson et al., 2015). Due to the growing evidence that the $\mathrm{AG}$ region is implicated in a range of cognitive activities including semantic cognition (Dehaene et al., 2003; Chambers et al., 2004; Cabeza et al., 2008; Cabeza et al., 2012; Noonan et al., 2013), an ROI was constructed from the coordinate of peak overlap between all tasks in a recent, large-scale meta-analysis (Humphreys and Lambon Ralph, 2014). Therefore, the selected ROIs included vATL ( $-39-639)$, aSTG/ STS (-519-12), IFG (-51 2412$)$, mPFC ( -94839$)$, pMTG $(-60-48$ $3)$, and AG ( $-48-6434)$. The aSTG ROI includes the dorsal bank of the anterior STS and is therefore labeled in a way that makes this apparent. Although there may be distinct functional subregions of aSTG and anterior STS, the specificity of the resting-state functional connectivity analyses used here is not sufficient to distinguish between these regions. Therefore, dissecting the contribution of these regions is beyond the scope of the current study. Future studies using more advanced methodology, such as higher-field intensity imaging, may be able investigate the interesting question of whether these regions show distinct connectivity. A smaller $(6 \mathrm{~mm})$ ROI was used to seed from the aMTG $(-453-27)$ to compare the role of this third intermediate ATL region to the vATL and aSTG/STS (without overlapping with these ROIs). The Euclidean distance between the aMTG and the two other ATL ROIs was approximately equal (vATL $16.16 \mathrm{~mm}$ vs aSTG/STS $17.23 \mathrm{~mm}$ ). ROI creation and analysis was conducted in the MarsBar toolbox (Brett et al., 2002).

\section{Data analysis}

Resting-state. Analysis was performed using statistical parametric mapping (SPM 8) software (Wellcome Trust Centre for Neuroimaging) and the Data Processing Assistant for Resting State fMRI (DPARSF Advanced Edition, version 2.3) toolbox (Chao-Gan and Yu-Feng, 2010). Distancedependent increases in correlations due to motion are a concern for resting-state functional connectivity analyses (Friston et al., 1996; Van Dijk et al., 2012; Yan et al., 2013; Power et al., 2014). For this reason, four methods shown to reduce these effects were used: censoring, global signal regression, 24-motion parameter regression, and scrubbing of highmotion time points. These methods are consistent with other restingstate studies and have been shown to greatly reduce the effects of motion (Weissenbacher et al., 2009; Anderson et al., 2011; Van Dijk et al., 2012; Yan et al., 2013; Power et al., 2014; Power et al., 2015).

The first two volumes from each run were automatically discarded to allow for magnetic saturation effects. SPM was used for slice timing correction, realignment, and coregistration to the individual's structural image. Participants were censored on the basis of a threshold of translation and rotation. Participants with $>3 \mathrm{~mm}$ translation or 1 degree of rotation were excluded from the analysis. This meant that only lowmotion participants were included in the analysis. Within DPARSF, nuisance covariates were regressed out and the images were normalized using DARTEL (Ashburner, 2007) and smoothed with an $8 \mathrm{~mm}$ fullwidth half maximum Gaussian kernel. The results were filtered at $0.01-$ $0.08 \mathrm{~Hz}$ (Satterthwaite et al., 2013). Nuisance covariates included 24 motion parameters calculated from the six original motion parameters using Volterra expansion (Friston et al., 1996). These have been shown to be better than the six parameters alone at decreasing motion effects (Yan et al., 2013; Power et al., 2014; Power et al., 2015). Time points with a $z$-score $>2.5$ from the mean global power or $>1 \mathrm{~mm}$ translation were identified as outliers using the ARtifact detection Tools software package (ART; www.nitrc.org/projects/artifact_detect). Each of these was entered as a covariate. White matter, CSF, and global tissue signal were covaried out and linear detrending was performed. Although regression of the global signal can cause spurious negative correlations, it greatly reduces motion-related artifacts (Weissenbacher et al., 2009; Anderson et al.,
2011; Yan et al., 2013; Power et al., 2014; Power et al., 2015). For this reason, analyses were restricted to positive correlations. Six participants were excluded due to having motion $>3 \mathrm{~mm}$ of translation, $1^{\circ}$ of rotation, or $<5$ min of data remaining after scrubbing high motion time points.

Seed-based functional connectivity analyses were performed from the ATL ROIs using DPARSF (Chao-Gan and Yu-Feng, 2010; Yan et al., 2013). Functional connectivity maps were $z$-score normalized. One sample $t$ tests were used to find areas displaying significant connectivity to the seed region. The resulting images were significant at a voxel-level threshold of 0.001 and FWE-corrected at the cluster level with a critical cluster level of 0.05 . Correlations between ROIs were examined to assess the connectivity between these regions. Comparisons between networks were conducted using paired $t$ tests on the $z$-score-normalized functional connectivity map. In addition, the correlation across the group between the seed and each semantic ROI was computed and the average of these values computed per individual. This gave a single statistic for each participant determining the connection of this seed to known semantic areas. This value was compared between seeds using paired $t$ tests to assess whether they were part of the same network. To be confident that motion was not a factor, the correlation between the main ROI results (the vATL to each semantic ROI) and the motion parameters was assessed. For each individual, the absolute sum of each of the six motion parameters used for realignment was computed, as well as the absolute sum of all three of the translation parameters and all three of the rotation parameters. The correlation between these eight values per individual and the correlations between the vATL and semantic ROIs were assessed. No significant relationships between motion and connectivity were found $(p>0.05)$.

PPI. To assess the functional connectivity of the vATL during an active semantic task, a PPI analysis was performed. The contrast of interest was the semantic task $>$ baseline letter-matching task. Analysis of the task data was performed using statistical parametric mapping (SPM 8) software (Wellcome Trust Centre for Neuroimaging). A $6 \mathrm{~mm}$ vATL ROI was created for use as a seed using the same coordinates as the restingstate analyses, a size consistent with prior PPI analyses (Ge and Han, 2008; Green et al., 2010; Veit et al., 2012). This seed was used to perform a whole-brain PPI analysis and the significance of the PPI effect within the a priori semantic regions was assessed. The same semantic regions in the IFG, mPFC, AG, and pMTG were used as $10 \mathrm{~mm}$ ROIs. Because the PPI and resting-state analyses are distinct and not directly comparable (due to a number of differences between the two methods), the size of the ROI was chosen independently for each analysis on the basis of prior investigations to be optimal for that analysis. This resulted in a smaller ROI for the PPI than the resting-state functional connectivity analysis (6 vs $10 \mathrm{~mm}$ ). To verify that this was not a critical factor in determining the overall conclusions of the study, the resting-state analyses were repeated with seed ROIs of $6 \mathrm{~mm}$ (identical to the PPI seed). The networks identified did not change. PPI analysis is based on the extraction of signal at the seed region and deconvolution with the hemodynamic response function. Areas with a significant amount of variance relating to the interaction between the physiological and the psychological contrast are identified in a regression analysis across the whole brain (Green et al., 2010; Friston, 2011). The whole-brain results were significant at a voxellevel threshold of 0.001 and FWE-corrected at the cluster level with a critical cluster level of 0.05 . ROI analyses were performed on the wholebrain result to assess whether the core network of regions considered a priori to be semantic were functionally connected in the semantic task.

Although PPI and resting-state functional connectivity analyses both measure functional connectivity, they involve very different computations and assumptions and therefore direct comparisons do not necessarily reveal state changes between rest and task. Resting-state functional connectivity analyses involve computing a simple correlation between the activation time series in the seed regions with all other regions or ROIs. The same technique cannot be used to assess the connectivity within the task data because changes in correlations may be caused by more basic changes in activity between the conditions; areas that are coactivated within a condition would appear to be correlated more regardless of their true influence on each other (Friston, 1994; Friston et al., 1997). PPI uses a regression model to assess which regions have activity 


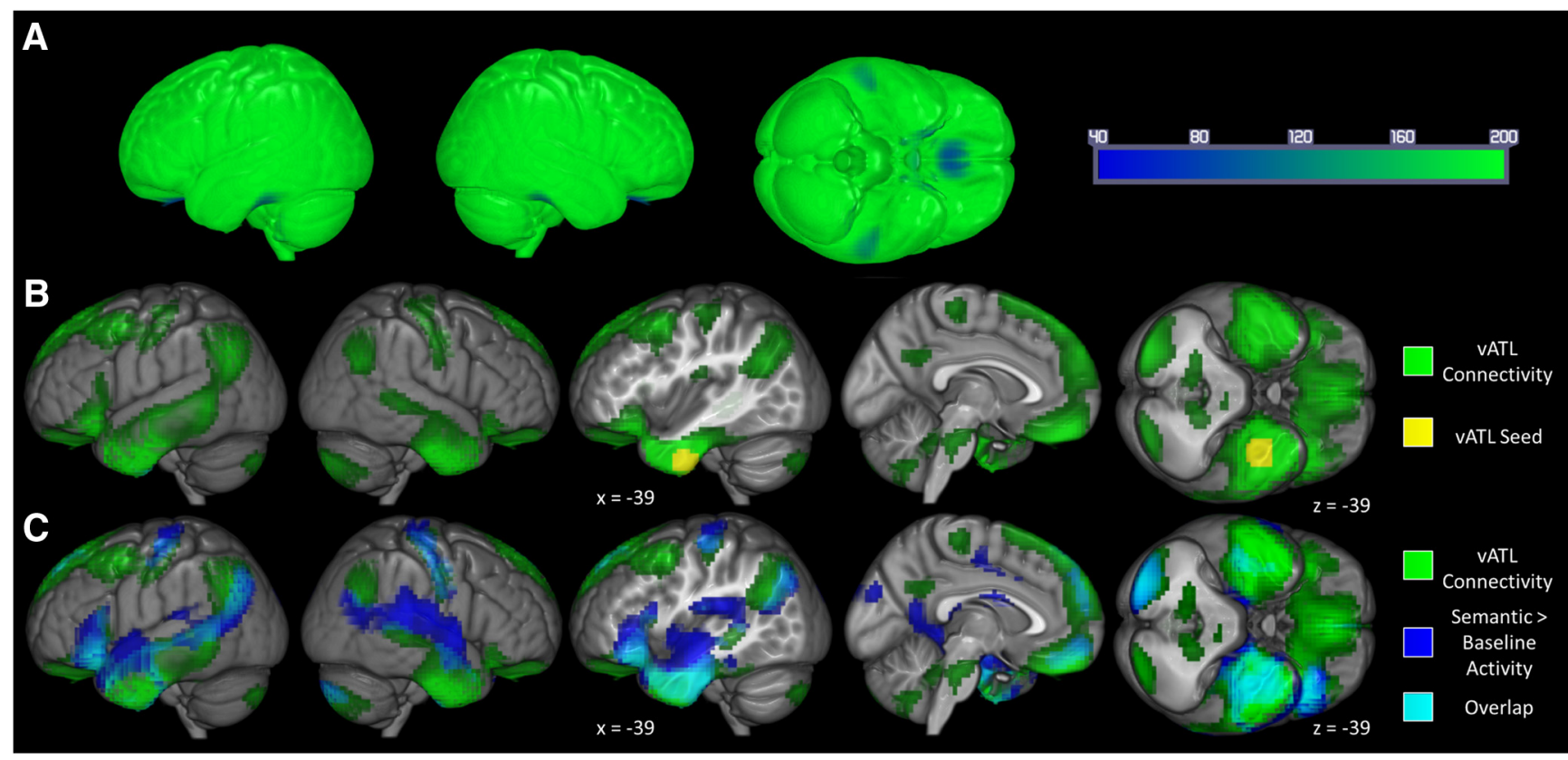

Figure 1. TSNR and vATL functional connectivity during rest. $A$, Average temporal signal-to-noise ratio for the resting-state EPI data in MNI space. The data have been realigned and normalized to MNI space to compute the average TSNR for the group; however, covariates have not been removed because this artificially changes the TSNR. The map is set at a threshold of 40, which is considered to be the minimum TSNR required to detect differences in signal reliably (Murphy et al., 2007; Simmons et al., 2010; Wang et al., 2013), and is displayed as a range from 40 (dark blue) to 200 (bright green). Use of the dual-echo technique meant signal reached the minimum threshold throughout the ATL and inferior frontal regions, with most of the brain far exceeding this with values $>200$. This meant that we had adequate signal to assess the functional connectivity of the areas commonly suffering from signal loss. Similar TSNR was demonstrated for the task data in Jackson et al. (2015). B, Resting-state functional connectivity of the vATL. Voxels displaying significant functional connectivity with the vATL are shown in green. The image was thresholded at 0.001 at the voxel level and an FWE-correction was performed at the cluster level with a critical cluster level of 0.05 . The vATL seed is overlaid in yellow. $\boldsymbol{C}$, The functional connectivity (green) of the vATL is shown with the activity from a univariate contrast of semantics over baseline (dark blue; Jackson et al., 2015). Overlap is shown in cyan. Both the connectivity and activity maps are thresholded at 0.001 at the voxel level and FWE-corrected at the cluster level. During rest, a network connects the vATL and other regions critical for semantic processing.

that can be predicted by the activity of the seed region in one condition more than in another after the difference in activity levels between conditions has been factored out. As such, PPI is directional, contrastive, and more stringent than standard resting-state functional connectivity (Friston, 1994; Fornito et al., 2012). Therefore, differences in the results of the resting-state functional correlation and PPI analyses may relate to the change between the task and rest state or to differences between the analysis methods and cannot be easily interpreted. Here, the results of the PPI analysis are provided as a complement to the resting-state functional connectivity to explore vATL connectivity and the relation between this connectivity and performance on a semantic (but not a high-level baseline) task.

The PPI analysis highlighted areas of the network that have been implicated in demanding semantic processing (see below). Therefore, to test an emergent hypothesis, an independent set of trials that experimentally manipulated the level of semantic control were analyzed. In the low control condition, foils were from a domain unrelated to the probe item, whereas, in the high control condition, foils were from the same category (e.g., barrel-box combined with the foil plum or seat). These trials were preprocessed in the same manner as the other task runs, but were not included in the PPI analysis (Jackson et al., 2015). A simple univariate analysis was performed contrasting activity in the high and low semantic control trials.

\section{Results}

Connectivity of semantic areas within the resting-state data The vATL seed showed functional connectivity during a resting state with a network of areas linked to semantic cognition (Fig. 1, Table 1). Significantly correlated regions were found within bilateral ATL, medial temporal lobe, pMTG, AG, frontal cortex, and insula. Further significant connectivity was found within bilateral middle and posterior cingulate and precuneus, as well as the right precentral and postcentral gyri and the cerebellum. Fig- ure $1 C$ shows the considerable overlap between this vATL-seeded resting-state network and the areas identified in a standard GLM analysis of the active semantic task. ROI analyses of the restingstate data showed that the vATL was functionally connected to all regions associated with multimodal semantic processing (IFG, $t_{(70)}=4.152, p<0.001 ; \mathrm{mPFC}, t_{(70)}=7.746, p<0.001 ; \mathrm{pMTG}$, $\left.t_{(70)}=7.255, p<0.05 ; \mathrm{AG}, t_{(70)}=7.885, p<0.001\right)$. Furthermore, all of these regions were functionally connected to each other $(p<0.001)$. This suggests that the vATL is functionally connected to a semantic network, as expected.

The aSTG/STS seed showed a functional connectivity pattern that differs greatly from the one observed for the vATL seed (Fig. 2, Table 1). Significant connectivity was found along the superior aspects of the temporal lobes bilaterally and in posterior temporal cortex. Bilateral inferior and middle frontal gyri, supramarginal gyrus, precentral and postcentral gyri, supplementary motor area (SMA), insula, and occipital cortex and left parahippocampal gyrus were also significantly connected. Significant positive correlations were found between the aSTG/STS and the IFG $\left(t_{(70)}=\right.$ $2.925, p<0.05)$ and pMTG $\left(t_{(70)}=5.293, p<0.001\right)$ ROIs only. To assess whether the vATL versus aSTG/STS results reflect separate networks, paired $t$ tests were performed (Fig. $2 B, C$ ). These distinct subcomponents included bilateral ATL, AG, and frontal cortex for the vATL seed versus aSTG/STS and IFG, precentral and postcentral gyri for the aSTG/STS seed versus vATL (Table 2 ). The distinct nature of the vATL and aSTG/STS networks was confirmed with a paired $t$ test comparing the correlation between the aSTG/STS and all other ROIs with the vATL and all other ROIs $\left(t_{(70)}=7.254, p<0.001\right)$. In summary, unlike the vATL, the aSTG/STS does not appear to be a core part of the multimodal 
Table 1. Significant clusters of functional connectivity during resting-state with subregions of the ATL

\begin{tabular}{|c|c|c|c|c|c|c|c|}
\hline \multirow{2}{*}{ Seed } & \multirow[b]{2}{*}{ Cluster region } & \multirow{2}{*}{$\begin{array}{l}\text { Cluster extent } \\
\text { (voxels) }\end{array}$} & \multirow{2}{*}{$\begin{array}{l}\text { Max } \\
\text { z value }\end{array}$} & \multirow{2}{*}{$\begin{array}{l}p \text { value } \\
\text { (FWE-corrected) }\end{array}$} & \multicolumn{3}{|c|}{ Peak MNI coordinate } \\
\hline & & & & & $x$ & $Y$ & $Z$ \\
\hline \multirow[t]{13}{*}{ vATL } & \multirow{3}{*}{$\begin{array}{l}\text { Bilateral frontotemporal cortex, LAG and } \\
\text { insula }\end{array}$} & \multirow[t]{3}{*}{11067} & \multirow[t]{3}{*}{$\operatorname{lnf}$} & \multirow[t]{3}{*}{$>0.001$} & -39 & -9 & -39 \\
\hline & & & & & 51 & -9 & -39 \\
\hline & & & & & 39 & -12 & -42 \\
\hline & Cerebellum & 157 & 6.71 & 0.005 & -21 & -87 & -42 \\
\hline & RAG & 191 & 6.41 & 0.002 & 60 & -60 & 30 \\
\hline & \multirow[t]{3}{*}{ R pre- $-\mathrm{CG}$ and post- $\mathrm{CG}$} & \multirow[t]{3}{*}{296} & \multirow[t]{3}{*}{6.13} & \multirow[t]{3}{*}{$>0.001$} & 60 & -6 & 45 \\
\hline & & & & & 51 & -18 & 60 \\
\hline & & & & & 57 & -15 & 54 \\
\hline & Bilateral PCC & 174 & 5.18 & \multirow[t]{2}{*}{0.003} & 3 & -27 & 63 \\
\hline & $\mathrm{RMCC}$ & & & & 12 & -9 & 48 \\
\hline & \multirow[t]{3}{*}{ LPCC and precuneus } & \multirow[t]{3}{*}{98} & 4.99 & 0.036 & 21 & -39 & 21 \\
\hline & & & & & 12 & -12 & 27 \\
\hline & & & & & 24 & -42 & 12 \\
\hline \multirow[t]{8}{*}{ aSTG/STS } & \multirow{3}{*}{$\begin{array}{l}\text { Bilateral STG, posterior temporal and } \\
\text { occipital cortex, IFG, pre-CG and } \\
\text { post-CG, SMA and insula }\end{array}$} & \multirow[t]{3}{*}{15437} & \multirow[t]{3}{*}{$\operatorname{lnf}$} & \multirow[t]{3}{*}{$>0.001$} & -48 & 12 & -12 \\
\hline & & & & & 54 & 6 & -12 \\
\hline & & & & & -39 & -6 & -12 \\
\hline & LMFG & 231 & 7.02 & 0.001 & -30 & 48 & 24 \\
\hline & \multirow[t]{3}{*}{ LPhG } & \multirow[t]{3}{*}{288} & 5.3 & $>0.001$ & 6 & -12 & -27 \\
\hline & & & & & -6 & -12 & -30 \\
\hline & & & & & -18 & -24 & -24 \\
\hline & R MFG & 94 & 4.97 & 0.043 & 30 & 48 & 24 \\
\hline aMTG & Bilateral frontotemporal cortex, thalamus, & 8897 & $\operatorname{lnf}$ & $>0.001$ & -45 & 3 & -24 \\
\hline & and insula & & & & 51 & 6 & -21 \\
\hline & & & & & 30 & -3 & -27 \\
\hline & LAG & 500 & 6.73 & $>0.001$ & -51 & -66 & 24 \\
\hline & & & & & -48 & -69 & 45 \\
\hline & Cerebellum & 190 & 6.46 & 0.002 & 24 & -78 & -33 \\
\hline & & & & & 45 & -78 & -39 \\
\hline & Bilateral PCC and precuneus & 452 & 6.22 & $>0.001$ & -3 & -51 & 33 \\
\hline & RAG & 219 & 5.93 & 0.001 & 60 & -57 & 30 \\
\hline & & & & & 54 & -69 & 36 \\
\hline & & & & & 45 & -54 & 27 \\
\hline & Cerebellum & 110 & 5.89 & 0.021 & -27 & -81 & -36 \\
\hline & Bilateral PCC & 218 & 4.93 & $>0.001$ & -6 & -30 & 63 \\
\hline & & & & & 6 & -27 & 63 \\
\hline & & & & & 15 & -33 & 69 \\
\hline
\end{tabular}

Clusters significant at 0.05 after FWE correction. Largest three peaks are listed per cluster. MTL, Medial temporal lobe; PhG, parahippocampal gyrus; MFG, middle frontal gyrus; PCC, posterior cingulate cortex; MCC, midcingulate cortex; CG, central gyrus.

semantic network in the resting-state data. Instead, it connects to multiple areas implicated in language and auditory processing.

The functional connectivity of the aMTG is shown in Figure $3 A$ (Table 1 ). Of the a priori ROIs, there was significant connectivity between the aMTG and the AG $\left(t_{(70)}=5.304, p<0.001\right)$ and $\operatorname{mPFC}\left(t_{(70)}=6.262, p<0.001\right)$ only. To assess whether the aMTG was part of a distinct network, areas with significantly greater connectivity to the aMTG than the aSTG/STS or vATL and vice versa were identified (Fig. $3 B, C$ ). The areas in the aMTG-seeded network overlapped substantially with those in the vATL-seeded network, albeit at a lower strength (but higher than obtained from the aSTG/STS seed). The regions demonstrating specific connectivity with the aSTG/STS seed were not generally apparent in either the aMTG-seeded or vATL-seeded networks. This suggests that the aMTG shows a similar yet slightly weaker connectivity pattern to the vATL and both are unlike the aSTG/ STS connectivity. These results were replicated with a larger aMTG seed showing that this was not merely a difference in power relating to the use of a smaller seed for the aMTG.

\section{Task-related semantic connectivity}

The functional connectivity of the vATL during explicit semantic judgments was determined using a PPI analysis. Figure 4 shows the whole-brain results (Table 3). Greater connectivity with the
vATL was found during a semantic than baseline task for regions, including anterior and posterior temporal cortex, angular gyrus, IFG, mPFC, and occipital cortex. The PPI highlighted areas known to be important in semantic processing that were also in the semantic network found during rest, including vATL, IFG, orbitofrontal cortex, pMTG, AG, and mPFC. ROI analysis of the PPI effect showed significant connectivity between the VATL and all the semantic ROIs $\left(\mathrm{AG}, t_{(70)}=3.952, p<0.001\right.$; IFG, $t_{(70)}=$ 5.871, $p<0.001$; pMTG, $t_{(70)}=3.927, p<0.001$; $\mathrm{mPFC}, t_{(70)}=$ $4.273, p<0.001)$. Therefore, the PPI confirmed the finding of a network of semantic areas connected to the vATL and further demonstrated the relation of this network to semantic processing in a constrained task.

The semantic networks identified using the resting-state and task data were not identical however; the PPI identified large areas of occipital and frontal cortex not found in the resting-state functional connectivity analysis. Activation of these regions has been associated previously with harder semantic trials either in terms of increased executive control demands (increased involvement of frontal regions) or increased interaction between semantic regions and lower order visual regions (in the occipital lobe). To assess this potential explanation, the PPI results were compared with an experimental contrast of trials requiring highand low-level semantic control (Jackson et al., 2015). The high $>$ 


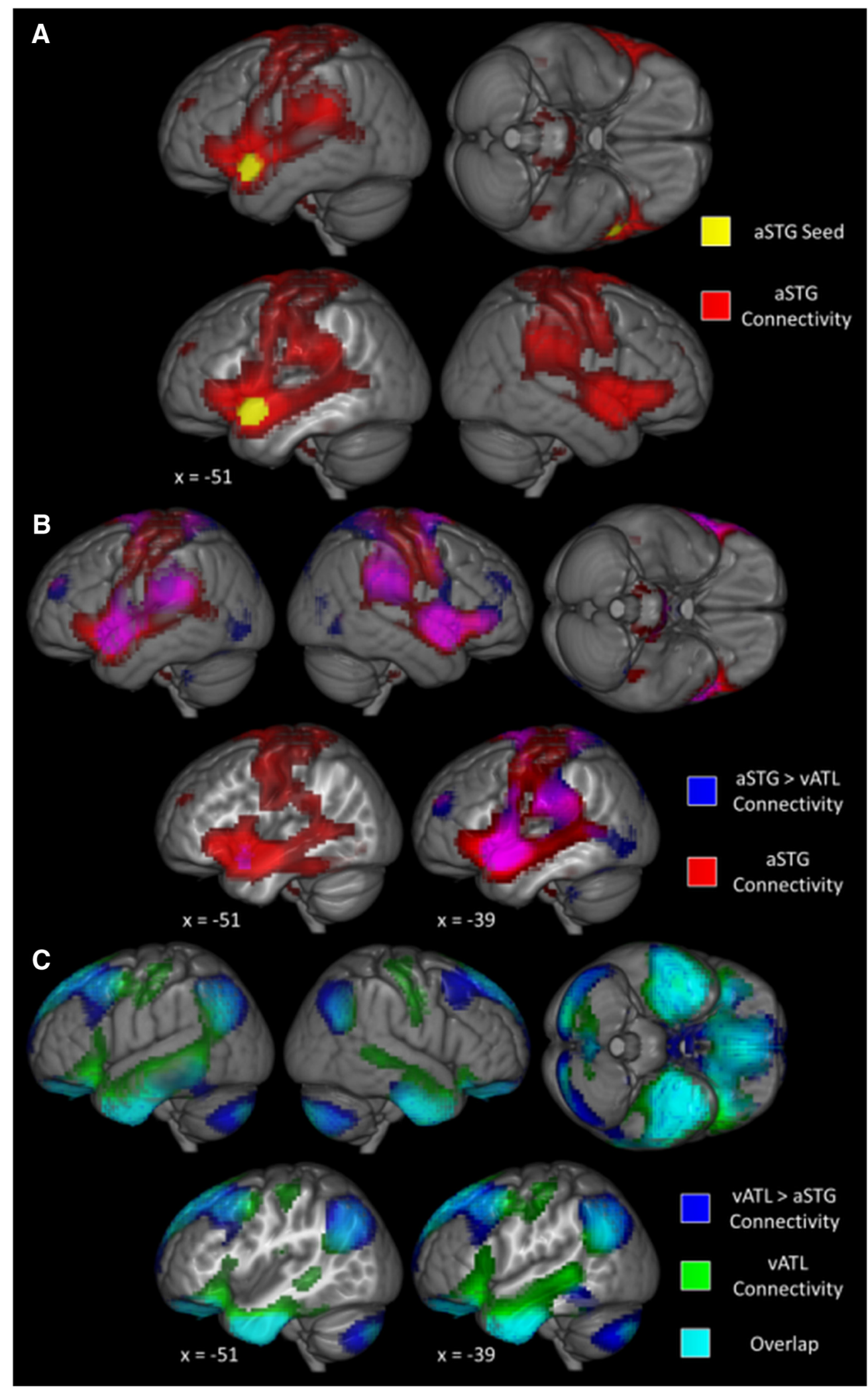

Figure 2. Resting-state connectivity of ATL subregions. $A$, Resting-state connectivity of the aSTG/STS. Voxels displaying significant functional connectivity with the aSTG/STS are shown in red. The image was thresholded at 0.001 at the voxel level and an FWE-correction was performed at the cluster level with a critical cluster level of 0.05 . The aSTG/STS seed is overlaid in yellow. $\boldsymbol{B}, \boldsymbol{C}$, Comparison of the functional connectivity of the vATL and aSTG/STS. B, Areas with significantly greater functional connectivity with the aSTG/STS (blue) are shown on top of the areas connected to the aSTG/STS (red). The image was thresholded at 0.001 at the voxel level and an FWE-correction was performed at the cluster level with a critical cluster level of 0.05 . Violet areas represent the regions of the aSTG/STS network that show significantly greater connectivity to the aSTG/STS than the vATL. C, Areas with significantly greater functional connectivity with the vATL (dark blue) are shown on top of the areas connected to the vATL (green). The image was thresholded at 0.001 at the voxel level and an FWE-correction was performed at the cluster level with a critical cluster level of 0.05 . Cyan areas represent the regions of the vATL network that show significantly greater connectivity to the vATL than the aSTG/STS. 
Table 2. Comparing the functional connectivity of the vATL and aSTG/STS

\begin{tabular}{|c|c|c|c|c|c|c|c|}
\hline \multirow[b]{2}{*}{ Contrast } & \multirow[b]{2}{*}{ Cluster region } & \multirow{2}{*}{$\begin{array}{l}\text { Cluster extent } \\
\text { (voxels) }\end{array}$} & \multirow{2}{*}{$\begin{array}{l}\text { Max } \\
z \text { value }\end{array}$} & \multirow{2}{*}{$\begin{array}{l}p \text { value } \\
\text { (FWE-corrected) }\end{array}$} & \multicolumn{3}{|c|}{ Peak MNI coordinate } \\
\hline & & & & & $x$ & $Y$ & $Z$ \\
\hline \multirow[t]{2}{*}{ vATL > aSTG/STS } & $\begin{array}{l}\text { Bilateral frontotemporal cortex, precu- } \\
\text { neus, PCC, and cerebellum, L AG }\end{array}$ & 15220 & Inf & $>0.001$ & -36 & -9 & -42 \\
\hline & RAG & 656 & Inf & $>0.001$ & 48 & -66 & 33 \\
\hline \multirow[t]{2}{*}{ aSTG/STS > vATL } & $\begin{array}{l}\text { Bilateral aSTG, IFG, pre-CG and post- } \\
\text { CG, MFG, mCC, SMA, caudate, SMG, } \\
\text { precuneus and occipital cortex }\end{array}$ & 17931 & $\operatorname{lnf}$ & $>0.001$ & $\begin{array}{r}-48 \\
51 \\
-39\end{array}$ & $\begin{array}{r}12 \\
9 \\
-6\end{array}$ & $\begin{array}{l}-12 \\
-12 \\
-12\end{array}$ \\
\hline & L PhG & 105 & 4.78 & 0.030 & $\begin{array}{r}-3 \\
-15\end{array}$ & $\begin{array}{r}-6 \\
-21\end{array}$ & $\begin{array}{l}-30 \\
-27\end{array}$ \\
\hline
\end{tabular}

Clusters significant at 0.05 after FWE-correction. Largest three peaks are listed per cluster. MTL, medial temporal lobe; PhG, parahippocampal gyrus; MFG, middle frontal gyrus; PCC, posterior cingulate cortex; MCC, mid cingulate cortex; $C$, central gyrus; SMG, supramarginal gyrus.

low semantic control contrast did indeed activate similar occipital and frontal regions, suggesting that these areas are recruited for more difficult semantic processing (Fig. 4B). These regions may have been identified in the PPI analysis and not the restingstate functional connectivity analysis due to either differences in the methodology or the change in state. Indeed, control processes may be more critical for task-based processing (which required explicit decisions and comparison of multiple items) than during rest. Alternatively, the PPI analysis may be more sensitive to the subtle variations in the network between conditions due to its contrastive nature that takes into account the basic activity pattern.

\section{Discussion}

The core aim of this study was to explore, for the first time, the connectivity of various ATL subregions across the brain with respect to their contributions to semantic cognition. This allowed a novel exploration of the functional network underlying semantic cognition. Compelling evidence for the function of this network was provided by demonstrating convergent functional connectivity under resting-state and task-active conditions. The vATL and aMTG (albeit slightly more weakly) areas were found to connect to a network of regions implicated in semantic cognition, including the bilateral ATL, IFG, mPFC, AG, and pMTG. In contrast, the aSTG/STS connected to auditory and language areas, including superior and posterior temporal cortex, IFG, SMA, supramarginal gyrus, premotor cortex, and precentral and postcentral gyri. During an active semantic judgment task, the vATL exhibited additional functional connectivity to frontal and occipital regions, which is upregulated when the processing demands of semantic tasks are increased.

\section{Semantic network}

The major finding from this study was that ventrolateral aspects of the ATL (vATL and aMTG) are functionally connected to a single semantic network, which is apparent both in resting-state and semantic task data. The identified network included regions implicated in semantic cognition, including bilateral ATL, IFG, $\mathrm{mPFC}, \mathrm{AG}$, and pMTG. Previous research has suggested that this broad neural network is composed of areas responsible for the representation and control of meaning. The ATL hub interacts with modality-specific regions to represent coherent concepts and the controlled retrieval and use of concepts is supported by frontal and parietal cortices (Thompson-Schill et al., 1999; Wagner et al., 2001; Patterson et al., 2007; Noonan et al., 2010; Jefferies, 2013; Noonan et al., 2013; Lambon Ralph, 2014).
Some of these frontoparietal areas may fulfill more general roles, for example, selection, retrieval, attention, working memory, or the processing of time-varying statistics (Petrides and Milner, 1982; Thompson-Schill et al., 1997; Nyberg et al., 2003; Humphreys and Lambon Ralph, 2014). Although the AG has been implicated in semantic representation (Geschwind, 1972; Binder et al., 2009; Binder and Desai, 2011), it is involved in diverse tasks, including the default mode network, and may relate to a more general cognitive process (Göbel et al., 2001; Cabeza et al., 2008; Cattaneo et al., 2009; Hutchinson et al., 2009; Cabeza et al., 2012; Humphreys and Lambon Ralph, 2014; Humphreys et al., 2015). Various meta-analyses have shown partial overlap between semantic (IFG and pMTG) and domain-general (PFC and inferior parietal) regions, also identified in frontoparietal control and multi-demand networks (Duncan, 2001, 2006; Vincent et al., 2008; Spreng et al., 2010; Leech et al., 2011; Noonan et al., 2013; Humphreys and Lambon Ralph, 2014). Our working assumption is that, although these areas may be primarily domain general, they are commonly engaged and contribute to semantic processing, particularly when this processing becomes demanding in nature.

The ventral and dorsal $\mathrm{mPFC}$ regions identified are active in semantic tasks (Binder et al., 2009), but involvement may depend on task demands or may be missed due to poor signal in ventral regions (Noonan et al., 2013; Halai et al., 2014). Additional connectivity of premotor and primary motor cortex may relate to implicit motor processing of internal language or motor planning. Connectivity was demonstrated between the vATL and the medial temporal lobe. Anterior hippocampus and perirhinal cortex were shown previously to connect functionally to the vATL, lateral orbitofrontal cortex, and amygdala (Ranganath and Ritchey, 2012; Ritchey et al., 2014). These regions were considered to be responsible for assessing the significance of newly encountered items based on existing knowledge (Ranganath and Ritchey, 2012). The current findings corroborate the connectivity between these areas, but suggest that these regions form part of a larger network reflecting semantic cognition more generally.

The connectivity of the semantic network can be interpreted in the context of known structural connections. A corticocortical evoked potential study showed fast transmission between the vATL and IFG (via the uncinate fasciculus) and pMTG (likely via inferior and middle longitudinal fasciculi), suggesting direct connections (Catani et al., 2002; Catani et al., 2003; Matsumoto et al., 2004; Binney et al., 2012; Von Der Heide et al., 2013). Although direct connections between the vATL and parietal cortex are ab- 


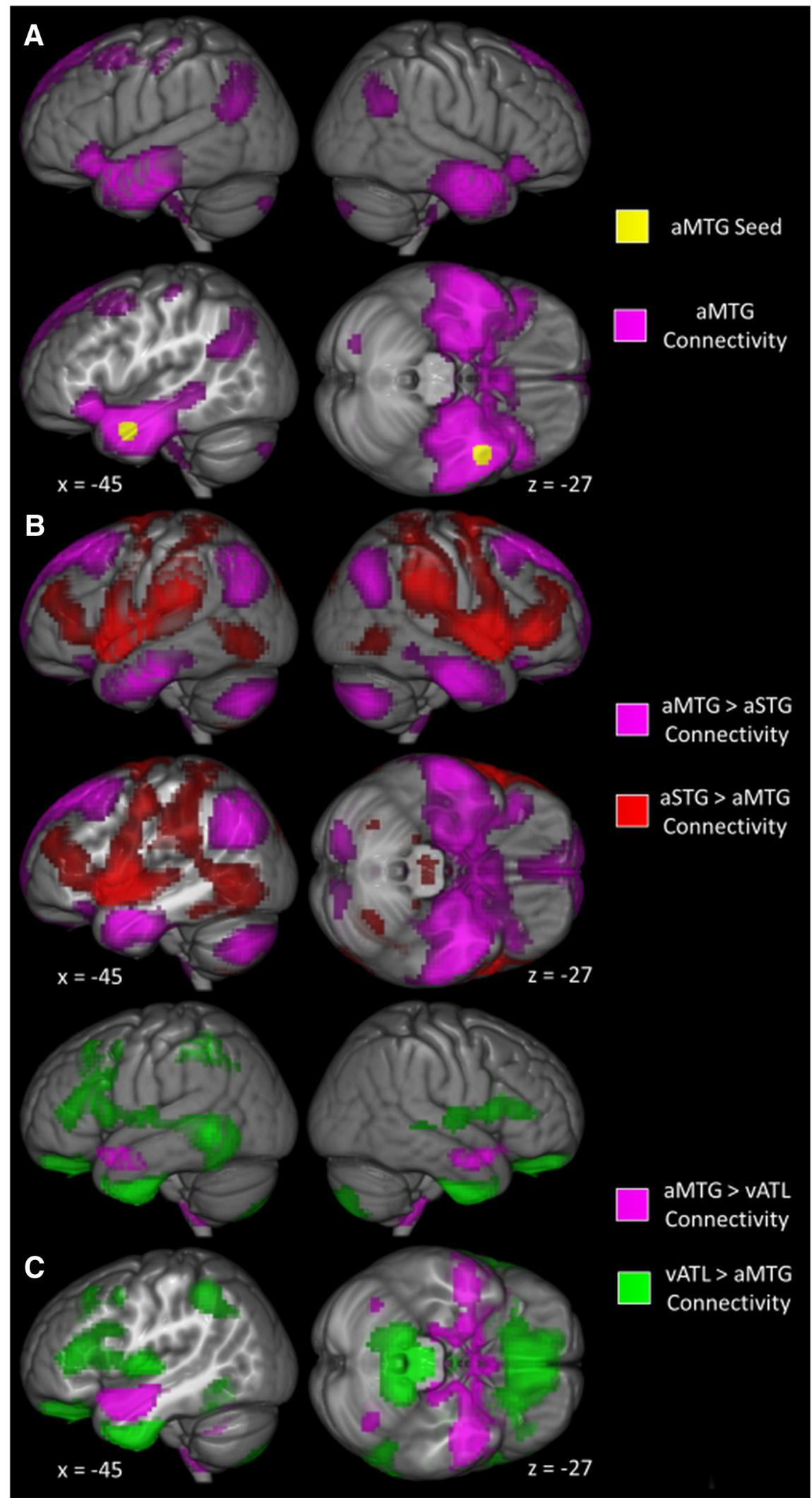

Figure 3. Functional connectivity of the aMTG during rest. $\boldsymbol{A}$, Areas significantly connected to the aMTG (violet). The aMTG seed is shown in yellow. The image was thresholded at 0.001 at the voxel level and an FEW-correction was performed at the cluster level with a critical cluster level of 0.05 . B, Comparison of the aMTG and aSTG/STS. Areas with significantly greater connectivity to the aMTG than the aSTG/STS are shown in violet and areas with significantly greater connectivity to the aSTG/STS than the aMTG are shown in red. C, Comparison of the aMTG and vATL. Areas with significantly greater connectivity to the aMTG than the vATL are shown in violet and areas with significantly greater connectivity to the vATL than the aMTG are shown in green. sent, indirect connections exist via the pMTG and arcuate fasciculus (Catani and Ffytche, 2005; Catani and Mesulam, 2008; Binney et al., 2012).

\section{Differential connectivity of subregions} of the ATL

There was a clear separation of connectivity patterns within the ATL. Areas critical for semantic cognition connected to the vATL. In sharp contrast, the aSTG/STS connected to bilateral STG, precentral and postcentral gyri, SMA, supramarginal gyrus, posterior temporal and premotor cortex, and inferior and middle frontal gyri. These areas are crucial for receptive and expressive language, particularly phonology and articulation, and are consistently included in traditional and modern models of language (Eggert, 1977; Berker et al., 1986; Hickok and Poeppel, 2004; Indefrey and Levelt, 2004; Vigneau et al., 2006; Hickok and Poeppel, 2007; Hickok, 2009; Hartwigsen et al., 2010; Price, 2010; Ueno et al., 2011; Price, 2012). These regions are structurally connected and may constitute distinct networks responsible for motor, tactile, and auditory processing, perhaps forming a phonological feedback loop between speech production and perception (Beckmann et al., 2005; Rauschecker and Scott, 2009; Price, 2010, 2012; Cloutman et al., 2013).

The connectivity of the aSTG/STS to regions associated with processing auditory input, phonology, and speech output fits well with the proposed function of the aSTG/STS and its structural connections to primary auditory regions (Morán et al., 1987; Binney et al., 2012). The aSTG is activated when processing meaningful environmental sounds and intelligible speech, suggesting a role in accessing meaning from auditory input (Scott et al., 2000; Spitsyna et al., 2006; Visser and Lambon Ralph, 2011). In addition, visually presented language can activate the aSTG, perhaps due to the visual language system commandeering the evolutionarily earlier auditory system and automatic conversion of orthography to phonology (Spitsyna et al., 2006; Skipper et al., 2011). Alternatively, both may involve a more general process, such as the use of sequential input to compute timeinvariant meanings (Ueno et al., 2011).

Posterior inferior temporal cortex and IFG were connected to both regions. Both networks reflect aspects of language processing, so may share regions integrating these aspects or sharing an input. Posterior inferior temporal cortex may interface between auditory and semantic 


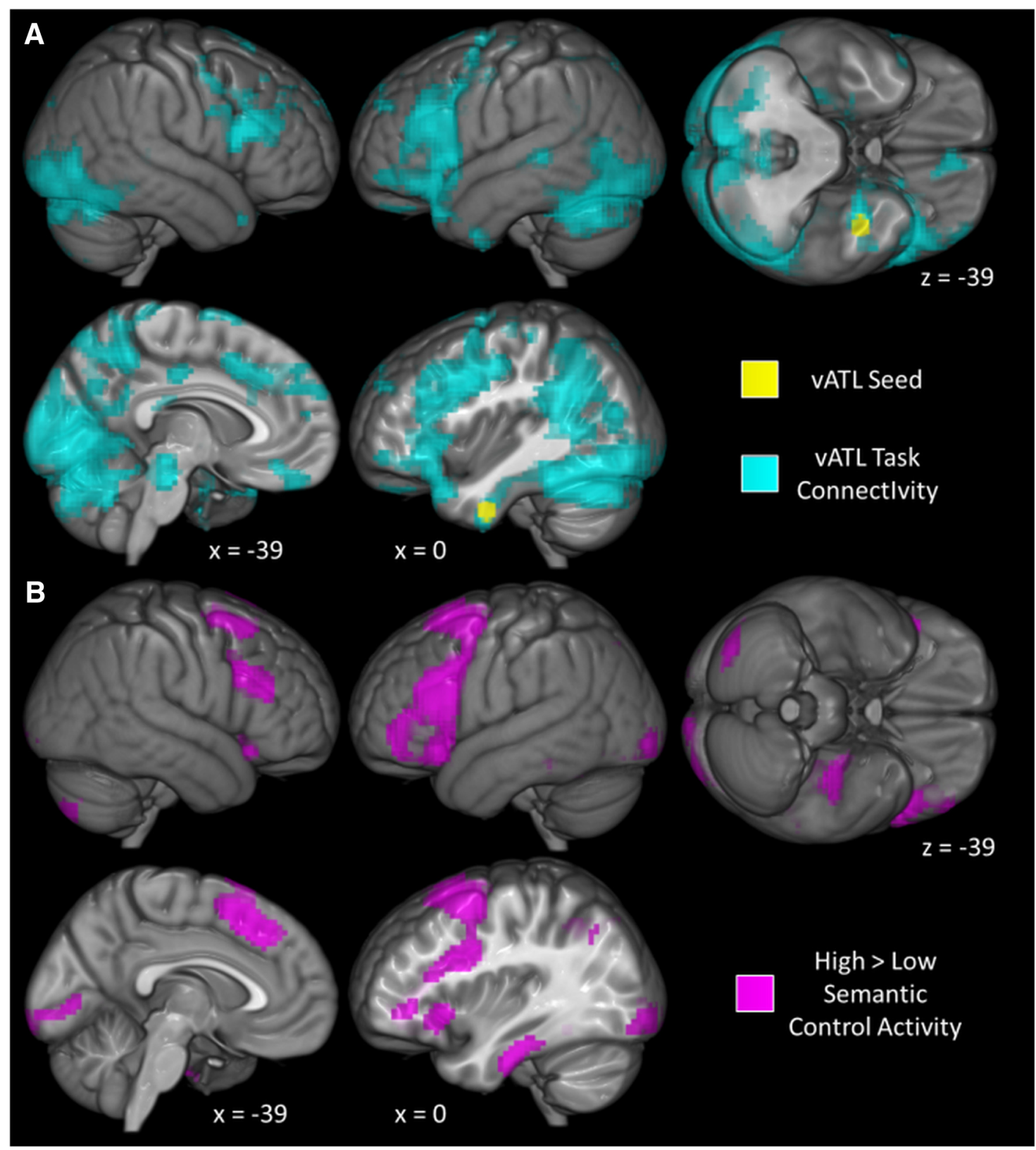

Figure 4. PPI analysis of vATL functional connectivity in semantic task $>$ letter-matching task. $A$, Results of the PPI analysis for semantic judgments $>$ letter matching. Voxels that have a significantly greater connection with the vATL during the semantic than the baseline task are shown in cyan. The vATL ROl is shown in yellow. Results are thresholded at 0.001 at the voxel level and FWE-corrected at the cluster level with a critical cluster level of 0.05 . B, Results of the contrast high semantic control $>$ low semantic control on the activity (violet) in Jackson et al. (2015). Results are thresholded at 0.001 at the voxel level and FWE-corrected at the cluster level with a critical cluster level of 0.05 .

Table 3. Peak areas of the PPI analyses showing significant functional connectivity with the vATL seed during semantic judgments $>$ letter matching

\begin{tabular}{|c|c|c|c|c|c|c|c|c|}
\hline \multirow[b]{2}{*}{ Seed region } & \multirow[b]{2}{*}{ Region } & \multirow[b]{2}{*}{ Cluster extent (voxels) } & \multirow[b]{2}{*}{ Max z-value } & \multirow[b]{2}{*}{$p$ value } & \multirow[b]{2}{*}{ Peak region } & \multicolumn{3}{|c|}{ Peak MNI coordinate } \\
\hline & & & & & & $x$ & $Y$ & $Z$ \\
\hline \multirow{4}{*}{ VATL } & L frontal and aSTS & 11005 & 5.48 & $>0.001$ & LpFG & -36 & -51 & -21 \\
\hline & Bilateral occipital, temporal and parietal and R frontal & 3193 & 4.92 & $>0.001$ & $\operatorname{Rinf} \mathrm{OFC}$ & 30 & 39 & -24 \\
\hline & Midbrain & 203 & 4.53 & $>0.001$ & Midbrain & -6 & -24 & -18 \\
\hline & R frontal & 345 & 4.09 & $>0.001$ & RIFG & 51 & 27 & 27 \\
\hline
\end{tabular}

Clusters significant at 0.05 after FWE-correction. Largest peak is listed per cluster. OFC, Orbitofrontal cortex; FG, fusiform gyrus.

processing (Hickok and Poeppel, 2007). The IFG is consistently implicated in both phonology and semantics and concurrent processing leads to great difficulty separating the distinct regions involved (Devlin et al., 2003; Gough et al., 2005). Therefore, the connectivity of the two regions may be interpreted as functionally distinct despite some overlap.

The functional connectivity of the aMTG is more similar to that of the vATL than the aSTG/STS. This suggests a role in mul- 
timodal semantic processing fitting its intermediate position between auditory and visual input (Morán et al., 1987; Binney et al., 2010; Visser et al., 2012). The graded differences between the MTG and ITG versus the sharper divide with the STG are mirrored directly by the variations of cytoarchitecture in this region (Brodmann, 2006). The rostral temporal pole may have a similar distinction, with superior and ventral subregions connected to distinct semantic and somatosensory networks resembling those identified here (Pascual et al., 2015).

\section{Functional connectivity within the task state}

vATL connectivity was very similar in the active semantic task and the resting-state data. Connectivity between regions responsible for multimodal semantic cognition (bilateral ATL, IFG, mPFC, AG, and pMTG) was demonstrated during the active task and the resting state. This convergence provides compelling evidence of a core network responsible for multimodal semantic cognition both during an explicit semantic task and when using semantic information in free thought. Additional connectivity to occipital and frontal regions was identified during the active semantic task. These differences are secondary compared with the finding of core semantic regions connected in both task and rest states. High correspondence between the two datasets, plus subtler differences, is consistent with prior investigations of statedependent connectivity (Jiang et al., 2004; Smith et al., 2009; Di et al., 2013; Cole et al., 2014). The differences may reflect real changes in connectivity between rest and task states. One difference between the states is the greater importance of visual stimuli during the active task. This could explain changes in connectivity between core semantic and occipital regions. Similarly, active tasks are likely to demand greater cognitive control. This could lead to heightened connectivity between the ATL and executiverelated frontal regions. This explanation was explored further by showing a high level of overlap between the PPI results and a univariate analysis of a semantic control manipulation. The PPI results seem to reflect the core semantic network plus greater connectivity to sensory input (occipital cortex) and controlrelated (frontal) regions. This effect may be heightened by the nature of PPI analyses. Because PPI contrasts two conditions with the main effect on activity regressed out, the results reflect the remaining interaction between the condition and physiological time series (Friston et al., 1997; Friston, 2011; O'Reilly et al., 2012). This may lend greater power to connections that vary between semantic trials.

\section{References}

Anderson JS, Druzgal TJ, Lopez-Larson M, Jeong EK, Desai K, YurgelunTodd D (2011) Network anticorrelations, global regression, and phaseshifted soft tissue correction. Hum Brain Mapp 32:919-934. CrossRef Medline

Ashburner J (2007) A fast diffeomorphic image registration algorithm. Neuroimage 38:95-113. CrossRef Medline

Beckmann CF, DeLuca M, Devlin JT, Smith SM (2005) Investigations into resting-state connectivity using independent component analysis. Philos Trans R Soc Lond B Biol Sci 360:1001-1013. CrossRef Medline

Berker EA, Berker AH, Smith A (1986) Translation of Broca 1865 report: localization of speech in the 3rd left frontal convolution. Arch Neurol 43:1065-1072. CrossRef Medline

Binder JR, Desai RH (2011) The neurobiology of semantic memory. Trends Cogn Sci 15:527-536. CrossRef Medline

Binder JR, Frost JA, Hammeke TA, Bellgowan PS, Rao SM, Cox RW (1999) Conceptual processing during the conscious resting state: a functional MRI study. J Cogn Neurosci 11:80-95. CrossRef Medline

Binder JR, Desai RH, Graves WW, Conant LL (2009) Where is the semantic system? A critical review and meta-analysis of 120 functional neuroimaging studies. Cereb Cortex 19:2767-2796. CrossRef Medline
Binney RJ, Embleton KV, Jefferies E, Parker GJ, Lambon Ralph MA (2010) The ventral and inferolateral aspects of the anterior temporal lobe are crucial in semantic memory: evidence from a novel direct comparison of distortion-corrected fMRI, rTMS, and semantic dementia. Cereb Cortex 20:2728-2738. CrossRef Medline

Binney RJ, Parker GJ, Lambon Ralph MA (2012) Convergent connectivity and graded specialization in the rostral human temporal lobe as revealed by diffusion-weighted imaging probabilistic tractography. J Cogn Neurosci 24:1998-2014. CrossRef Medline

Bressler SL, Menon V (2010) Large-scale brain networks in cognition: emerging methods and principles. Trends Cogn Sci 14:277-290. CrossRef Medline

Brett M, Anton JL, Valabregue R, Poline JB (2002) Region of interest analysis using an SPM toolbox [abstract]. Presented at the 8th International Conference on Functional Mapping of the Human Brain, June 2-6, 2002, Sendai, Japan Available on CD-ROM in Neuroimage, Vol 16, No 2.

Brodmann K (2006) Brodmann's localisation in the cerebral cortex: the principles of comparative localisation in the cerebral cortex, based on cytoarchitectonics. New York: Springer.

Butler CR, Brambati SM, Miller BL, Gorno-Tempini ML (2009) The neural correlates of verbal and nonverbal semantic processing deficits in neurodegenerative disease. Cogn Behav Neurol 22:73-80. CrossRef Medline

Cabeza R, Ciaramelli E, Olson IR, Moscovitch M (2008) The parietal cortex and episodic memory: an attentional account. Nat Rev Neurosci 9: 613-625. CrossRef Medline

Cabeza R, Ciaramelli E, Moscovitch M (2012) Cognitive contributions of the ventral parietal cortex: an integrative theoretical account. Trends Cogn Sci 16:338-352. CrossRef Medline

Catani M, Ffytche DH (2005) The rises and falls of disconnection syndromes. Brain 128:2224-2239. CrossRef Medline

Catani M, Mesulam M (2008) The arcuate fasciculus and the disconnection theme in language and aphasia: history and current state. Cortex 44: 953-961. CrossRef Medline

Catani M, Howard RJ, Pajevic S, Jones DK (2002) Virtual in vivo interactive dissection of white matter fasciculi in the human brain. Neuroimage 17: 77-94. CrossRef Medline

Catani M, Jones DK, Donato R, Ffytche DH (2003) Occipito-temporal connections in the human brain. Brain 126:2093-2107. CrossRef Medline

Cattaneo Z, Vecchi T, Pascual-Leone A, Silvanto J (2009) Contrasting early visual cortical activation states causally involved in visual imagery and short-term memory. Eur J Neurosci 30:1393-1400. CrossRef Medline

Chambers CD, Stokes MG, Mattingley JB (2004) Modality-specific control of strategic spatial attention in parietal cortex. Neuron 44:925-930. CrossRef Medline

Chao-Gan Y, Yu-Feng Z (2010) DPARSF: A MATLAB Toolbox for "pipeline" data analysis of resting-state fMRI. Front Syst Neurosci 4:13-13. Medline

Cloutman LL, Binney RJ, Morris DM, Parker GJ, Lambon Ralph MA (2013) Using in vivo probabilistic tractography to reveal two segregated dorsal "language-cognitive' pathways in the human brain. Brain Lang 127: 230-240. CrossRef Medline

Cole MW, Bassett DS, Power JD, Braver TS, Petersen SE (2014) Intrinsic and task-evoked network architectures of the human brain. Neuron 83: 238-251. CrossRef Medline

Dehaene S, Piazza M, Pinel P, Cohen L (2003) Three parietal circuits for number processing. Cogn Neuropsychol 20:487-506. CrossRef Medline

Devlin JT, Matthews PM, Rushworth MF (2003) Semantic processing in the left inferior prefrontal cortex: a combined functional magnetic resonance imaging and transcranial magnetic stimulation study. J Cogn Neurosci 15:71-84. CrossRef Medline

Di X, Gohel S, Kim EH, Biswal BB (2013) Task vs. rest-different network configurations between the coactivation and the resting-state brain networks. Front Hum Neurosci 7.

Ding SL, Van Hoesen GW, Cassell MD, Poremba A (2009) Parcellation of human temporal polar cortex: a combined analysis of multiple cytoarchitectonic, chemoarchitectonic, and pathological markers. J Comp Neurol 514:595-623. CrossRef Medline

Duffau H, Gatignol P, Mandonnet E, Peruzzi P, Tzourio-Mazoyer N, Capelle L (2005) New insights into the anatomo-functional connectivity of the semantic system: a study using cortico-subcortical electrostimulations. Brain 128:797-810. Medline 
Duncan J (2001) An adaptive coding model of neural function in prefrontal cortex. Nat Rev Neurosci 2:820-829. CrossRef Medline

Duncan J (2006) Brain mechanisms of attention. Q J Exp Psychol (Hove) 59(1):2-27. CrossRef Medline

Eggert GH (1977) Wernicke's works on aphasia: a sourcebook and review. The Hague: Mouton.

Embleton KV, Haroon HA, Morris DM, Lambon Ralph MA, Parker GJ (2010) Distortion correction for diffusion-weighted MRI tractography and fMRI in the temporal lobes. Hum Brain Mapp 31:1570-1587. CrossRef Medline

Fornito A, Harrison BJ, Zalesky A, Simons JS (2012) Competitive and cooperative dynamics of large-scale brain functional networks supporting recollection. Proc Natl Acad Sci U S A 109:12788-12793. CrossRef Medline

Friederici AD (2011) The brain basis of language processing: from structure to function. Physiol Rev 91:1357-1392. CrossRef Medline

Friston KJ (1994) Functional and effective connectivity in neuroimaging: a synthesis. Hum Brain Mapp 2:56-78. CrossRef

Friston KJ (2011) Functional and effective connectivity: a review. Brain Connect 1:13-36. CrossRef Medline

Friston KJ, Williams S, Howard R, Frackowiak RS, Turner R (1996) Movement-related effects in fMRI time-series. Magn Reson Med 35: 346-355. CrossRef Medline

Friston KJ, Buechel C, Fink GR, Morris J, Rolls E, Dolan RJ (1997) Psychophysiological and modulatory interactions in neuroimaging. Neuroimage 6:218-229. CrossRef Medline

Ge J, Han S (2008) Distinct neurocognitive strategies for comprehensions of human and artificial intelligence. PLoS One 3:e2797. CrossRef Medline

Geschwind N (1972) Language and brain. Scientific American 226:76-83. CrossRef Medline

Göbel S, Walsh V, Rushworth MF (2001) The mental number line and the human angular gyrus. Neuroimage 14:1278-1289. CrossRef Medline

Gough PM, Nobre AC, Devlin JT (2005) Dissociating linguistic processes in the left inferior frontal cortex with transcranial magnetic stimulation. J Neurosci 25:8010-8016. CrossRef Medline

Green S, Ralph MA, Moll J, Stamatakis EA, Grafman J, Zahn R (2010) Selective functional integration between anterior temporal and distinct fronto-mesolimbic regions during guilt and indignation. Neuroimage 52: 1720-1726. CrossRef Medline

Halai AD, Welbourne SR, Embleton K, Parkes LM (2014) A comparison of dual-echo and spin-echo fMRI of the inferior temporal lobe. Hum Brain Mapp 35:4118-4128. CrossRef Medline

Hartwigsen G, Baumgaertner A, Price CJ, Koehnke M, Ulmer S, Siebner HR (2010) Phonological decisions require both the left and right supramarginal gyri. Proc Natl Acad Sci U S A 107:16494-16499. CrossRef Medline

Hickok G (2009) The functional neuroanatomy of language. Phys Life Rev 6:121-143. CrossRef Medline

Hickok G, Poeppel D (2004) Dorsal and ventral streams: a framework for understanding aspects of the functional anatomy of language. Cognition 92:67-99. CrossRef Medline

Hickok G, Poeppel D (2007) The cortical organization of speech processing. Nat Rev Neurosci 8:393-402. CrossRef Medline

Hoffman P, Binney RJ, Lambon Ralph MA (2015) Differing contributions of inferior prefrontal and anterior temporal cortex to concrete and abstract conceptual knowledge. Cortex 63:250-266. CrossRef Medline

Humphreys G, Lambon Ralph MA (2014) Fusion and fission of cognitive functions in the human parietal cortex. Cereb Cortex.

Humphreys GF, Hoffman P, Visser M, Binney RJ, Lambon Ralph MA (2015) Establishing task- and modality-dependent dissociations between the semantic and default mode networks. Proc Natl Acad Sci U S A 112:78577862. CrossRef Medline

Hutchinson JB, Uncapher MR, Wagner AD (2009) Posterior parietal cortex and episodic retrieval: convergent and divergent effects of attention and memory. Learn Mem 16:343-356. CrossRef Medline

Indefrey P, Levelt WJ (2004) The spatial and temporal signatures of word production components. Cognition 92:101-144. CrossRef Medline

Jackson RL, Hoffman P, Pobric G, Lambon Ralph MA (2015) The nature and neural correlates of semantic association versus conceptual similarity. Cereb Cortex 25:4319-4333. CrossRef Medline

Jefferies E (2013) The neural basis of semantic cognition: Converging evidence from neuropsychology, neuroimaging and TMS. Cortex 49: 611-625. CrossRef Medline
Jiang T, He Y, Zang Y, Weng X (2004) Modulation of functional connectivity during the resting state and the motor task. Hum Brain Mapp 22: 63-71. CrossRef Medline

Lambon Ralph MA (2014) Neurocognitive insights on conceptual knowledge and its breakdown. Philos Trans R Soc Lond B Biol Sci 369: 20120392-20120392. Medline

Lambon Ralph MA, Pobric G, Jefferies E (2009) Conceptual knowledge is underpinned by the temporal pole bilaterally: convergent evidence from rTMS. Cereb Cortex 19:832-838. CrossRef Medline

Leech R, Kamourieh S, Beckmann CF, Sharp DJ (2011) Fractionating the default mode network: Distinct contributions of the ventral and dorsal posterior cingulate cortex to cognitive control. J Neurosci 31:3217-3224. CrossRef Medline

Lüders H, Lesser RP, Hahn J, Dinner DS, Morris H, Resor S, Harrison M (1986) Basal temporal language area demonstrated by electricalstimulation. Neurology 36:505-510. CrossRef Medline

Lüders HO, Lesser RP, Hahn J, Dinner DS, Morris HH, Wyllie E, Godoy J (1991) Basal temporal language area. Brain 114:743-754. CrossRef Medline

Matsumoto R, Nair DR, LaPresto E, Najm I, Bingaman W, Shibasaki H, Lüders HO (2004) Functional connectivity in the human language system: a cortico-cortical evoked potential study. Brain 127:2316-2330. CrossRef Medline

McIntosh AR (1999) Mapping cognition to the brain through neural interactions. Memory 7:523-548. CrossRef Medline

Meehan TP, Bressler SL (2012) Neurocognitive networks: Findings, models, and theory. Neurosci Biobehav Rev 36:2232-2247. CrossRef Medline

Mesulam MM (1990) Large scale neurocognitive networks and distributedprocessing for attention, language, and memory. Ann Neurol 28: 597-613. CrossRef Medline

Mesulam MM, Rogalski EJ, Wieneke C, Hurley RS, Geula C, Bigio EH, Thompson CK, Weintraub S (2014) Primary progressive aphasia and the evolving neurology of the language network. Nat Rev Neurol 10: 554-569. CrossRef Medline

Mion M, Patterson K, Acosta-Cabronero J, Pengas G, Izquierdo-Garcia D, Hong YT, Fryer TD, Williams GB, Hodges JR, Nestor PJ (2010) What the left and right anterior fusiform gyri tell us about semantic memory. Brain 133:3256-3268. CrossRef Medline

Morán MA, Mufson EJ, Mesulam MM (1987) Neural inputs into the temporopolar cortex of the rhesus monkey. J Comp Neurol 256:88-103. CrossRef Medline

Murphy K, Bodurka J, Bandettini PA (2007) How long to scan? The relationship between fMRI temporal signal to noise ratio and necessary scan duration. Neuroimage 34:565-574. CrossRef Medline

Noonan KA, Jefferies E, Corbett F, Lambon Ralph MA (2010) Elucidating the nature of deregulated semantic cognition in semantic aphasia: evidence for the roles of prefrontal and temporo-parietal cortices. J Cogn Neurosci 22:1597-1613. CrossRef Medline

Noonan KA, Jefferies E, Visser M, Lambon Ralph MA (2013) Going beyond inferior prefrontal involvement in semantic control: Evidence for the additional contribution of dorsal angular gyrus and posterior middle temporal cortex. J Cogn Neurosci 25:1824-1850. CrossRef Medline

Nyberg L, Marklund P, Persson J, Cabeza R, Forkstam C, Petersson KM, Ingvar M (2003) Common prefrontal activations during working memory, episodic memory, and semantic memory. Neuropsychologia 41: 371-377. CrossRef Medline

Oldfield RC (1971) The assessment and analysis of handedness: the Edinburgh inventory. Neuropsychologia 9:97-113. CrossRef Medline

O’Reilly JX, Woolrich MW, Behrens TE, Smith SM, Johansen-Berg H (2012) Tools of the trade: psychophysiological interactions and functional connectivity. Soc Cogn Affect Neurosci 7:604-609. CrossRef Medline

Pascual B, Masdeu JC, Hollenbeck M, Makris N, Insausti R, Ding SL, Dickerson BC (2015) Large-scale brain networks of the human left temporal pole: a functional connectivity MRI study. Cereb Cortex 25:680-702. Medline

Patterson K, Nestor PJ, Rogers TT (2007) Where do you know what you know? The representation of semantic knowledge in the human brain. Nat Rev Neurosci 8:976-987. CrossRef Medline

Petrides M, Milner B (1982) Deficits on subject-ordered tasks after frontallobe and temporal-lobe lesions in man. Neuropsychologia 20:249-262. CrossRef Medline

Pobric G, Jefferies E, Ralph MA (2007) Anterior temporal lobes mediate 
semantic representation: mimicking semantic dementia by using rTMS in normal participants. Proc Natl Acad Sci U S A 104:20137-20141. CrossRef Medline

Poser BA, Norris DG (2007) Fast spin echo sequences for BOLD functional MRI. MAGMA 20:11-17. CrossRef Medline

Poser BA, Norris DG (2009) Investigating the benefits of multiecho EPI for fMRI at 7 T. Neuroimage 45:1162-1172. CrossRef Medline

Poser BA, Versluis MJ, Hoogduin JM, Norris DG (2006) BOLD contrast sensitivity enhancement and artifact reduction with multiecho EPI: parallel-acquired inhomogeneity-desensitized fMRI. Magn Reson Med 55:1227-1235. CrossRef Medline

Power JD, Mitra A, Laumann TO, Snyder AZ, Schlaggar BL, Petersen SE (2014) Methods to detect, characterize, and remove motion artifact in resting state fMRI. Neuroimage 84:320-341. CrossRef Medline

Power JD, Schlaggar BL, Petersen SE (2015) Recent progress and outstanding issues in motion correction in resting state fMRI. Neuroimage 105: 536-551. CrossRef Medline

Price CJ (2010) The anatomy of language: a review of 100 fMRI studies published in 2009. Ann N Y Acad Sci 1191:62-88. CrossRef Medline

Price CJ (2012) A review and synthesis of the first 20 years of PET and fMRI studies of heard speech, spoken language and reading. Neuroimage 62: 816-847. CrossRef Medline

Ranganath C, Ritchey M (2012) Two cortical systems for memory-guided behaviour. Nat Rev Neurosci 13:713-726. CrossRef Medline

Rauschecker JP, Scott SK (2009) Maps and streams in the auditory cortex: nonhuman primates illuminate human speech processing. Nat Neurosci 12:718-724. CrossRef Medline

Ritchey M, Yonelinas AP, Ranganath C (2014) Functional connectivity relationships predict similarities in task activation and pattern information during associative memory encoding. J Cogn Neurosci 26:1085-1099. CrossRef Medline

Rogers TT, Lambon Ralph MA, Garrard P, Bozeat S, McClelland JL, Hodges JR, Patterson K (2004) Structure and deterioration of semantic memory: A neuropsychological and computational investigation. Psychol Rev 111:205-235. CrossRef Medline

Satterthwaite TD, Elliott MA, Gerraty RT, Ruparel K, Loughead J, Calkins ME, Eickhoff SB, Hakonarson H, Gur RC, Gur RE, Wolf DH (2013) An improved framework for confound regression and filtering for control of motion artifact in the preprocessing of resting-state functional connectivity data. Neuroimage 64:240-256. CrossRef Medline

Scott SK, Blank CC, Rosen S, Wise RJ (2000) Identification of a pathway for intelligible speech in the left temporal lobe. Brain 123:2400-2406. CrossRef Medline

Shimotake A, Matsumoto R, Ueno T, Kunieda T, Saito S, Hoffman P, Kikuchi T, Fukuyama H, Miyamoto S, Takahashi R, Ikeda A, Lambon Ralph MA (2015) Direct exploration of the ventral anterior temporal lobe in semantic memory: cortical stimulation and local field potential evidence from subdural grid electrodes. Cereb Cortex 25:3802-3817. Medline

Simmons WK, Reddish M, Bellgowan PS, Martin A (2010) The selectivity and functional connectivity of the anterior temporal lobes. Cereb Cortex 20:813-825. CrossRef Medline

Skipper LM, Ross LA, Olson IR (2011) Sensory and semantic category subdivisions within the anterior temporal lobes. Neuropsychologia 49: 3419-3429. CrossRef Medline

Smith SM, Fox PT, Miller KL, Glahn DC, Fox PM, Mackay CE, Filippini N, Watkins KE, Toro R, Laird AR, Beckmann CF (2009) Correspondence of the brain's functional architecture during activation and rest. Proc Natl Acad Sci U S A 106:13040-13045. CrossRef Medline

Spitsyna G, Warren JE, Scott SK, Turkheimer FE, Wise RJ (2006) Converging language streams in the human temporal lobe. J Neurosci 26: 7328-7336. CrossRef Medline

Spreng RN, Stevens WD, Chamberlain JP, Gilmore AW, Schacter DL (2010) Default network activity, coupled with the frontoparietal control network, supports goal-directed cognition. Neuroimage 53:303-317. CrossRef Medline
Thompson-Schill SL, D’Esposito M, Aguirre GK, Farah MJ (1997) Role of left inferior prefrontal cortex in retrieval of semantic knowledge: A reevaluation. Proc Natl Acad Sci U S A 94:14792-14797. CrossRef Medline

Thompson-Schill SL, D'Esposito M, Kan IP (1999) Double dissociation of frontal and temporal lobe contributions to semantic memory. In: Cognitive Neuroscience Society Annual Meeting, pp 23-23.

Turken AU, Dronkers NF (2011) The neural architecture of the language comprehension network: converging evidence from lesion and connectivity analyses. Front Syst Neurosci 5:1-20. Medline

Ueno T, Saito S, Rogers TT, Lambon Ralph MA (2011) Lichtheim 2: synthesizing aphasia and the neural basis of language in a neurocomputational model of the dual dorsal-ventral language pathways. Neuron 72:385-396. CrossRef Medline

Van Dijk KR, Sabuncu MR, Buckner RL (2012) The influence of head motion on intrinsic functional connectivity MRI. Neuroimage 59:431-438. CrossRef Medline

Veit R, Singh V, Sitaram R, Caria A, Rauss K, Birbaumer N (2012) Using real-time fMRI to learn voluntary regulation of the anterior insula in the presence of threat-related stimuli. Soc Cogn Affect Neurosci 7:623-634. CrossRef Medline

Vigneau M, Beaucousin V, Hervé PY, Duffau H, Crivello F, Houdé O, Mazoyer B, Tzourio-Mazoyer N (2006) Meta-analyzing left hemisphere language areas: phonology, semantics, and sentence processing. Neuroimage 30:1414-1432. CrossRef Medline

Vincent JL, Kahn I, Snyder AZ, Raichle ME, Buckner RL (2008) Evidence for a frontoparietal control system revealed by intrinsic functional connectivity. J Neurophysiol 100:3328-3342. CrossRef Medline

Visser M, Lambon Ralph MA (2011) Differential contributions of bilateral ventral anterior temporal lobe and left anterior superior temporal gyrus to semantic processes. J Cogn Neurosci 23:3121-3131. CrossRef Medline

Visser M, Jefferies E, Lambon Ralph MA (2010a) Semantic processing in the anterior temporal lobes: a meta-analysis of the functional neuroimaging literature. J Cogn Neurosci 22:1083-1094. CrossRef Medline

Visser M, Embleton KV, Jefferies E, Parker GJ, Ralph MA (2010b) The inferior, anterior temporal lobes and semantic memory clarified: Novel evidence from distortion-corrected fMRI. Neuropsychologia 48:16891696. CrossRef Medline

Visser M, Jefferies E, Embleton KV, Lambon Ralph MA (2012) Both the middle temporal gyrus and the ventral anterior temporal area are crucial for multimodal semantic processing: distortion-corrected fMRI evidence for a double gradient of information convergence in the temporal lobes. J Cogn Neurosci 24:1766-1778. CrossRef Medline

Von Der Heide RJ, Skipper LM, Klobusicky E, Olson IR (2013) Dissecting the uncinate fasciculus: disorders, controversies and a hypothesis. Brain 136:1692-1707. CrossRef Medline

Wagner AD, Paré-Blagoev EJ, Clark J, Poldrack RA (2001) Recovering meaning: left prefrontal cortex guides controlled semantic retrieval. Neuron 31:329-338. CrossRef Medline

Wang B, Yan T, Wu J, Chen K, Imajyo S, Ohno S, Kanazawa S (2013) Regional neural response differences in the determination of faces or houses positioned in a wide visual field. PLoS One 8:e72728. CrossRef Medline

Weissenbacher A, Kasess C, Gerstl F, Lanzenberger R, Moser E, Windischberger C (2009) Correlations and anticorrelations in resting-state functional connectivity MRI: a quantitative comparison of preprocessing strategies. Neuroimage 47:1408-1416. CrossRef Medline

Wig GS, Laumann TO, Petersen SE (2014) An approach for parcellating human cortical areas using resting-state correlations. Neuroimage 93: 276-291. CrossRef Medline

Yan CG, Cheung B, Kelly C, Colcombe S, Craddock RC, Di Martino A, Li Q, Zuo XN, Castellanos FX, Milham MP (2013) A comprehensive assessment of regional variation in the impact of head micromovements on functional connectomics. Neuroimage 76:183-201. CrossRef Medline

Zuo XN, Ehmke R, Mennes M, Imperati D, Castellanos FX, Sporns O, Milham MP (2012) Network centrality in the human functional connectome. Cereb Cortex 22:1862-1875. CrossRef Medline 